\title{
The Ameliorative Antioxidant Role of Quercetin in Experimental Model of non Alcoholic Steatohepatitis in Male Rats
}

\author{
M.A.Marzouk, S.A.Hussein, Y.A.Elsenosy, M.K.Mahfouz and A.D.A.EIMageid \\ Biochemistry Dept., Faculty of Veterinary Medicine, Benha Univ., Egypt \\ E-Mail:dr_mohammed_marzouk@yahoo.com
}

\begin{abstract}
Quercetin (QUR) is a polyphenolic phytochemical flavonoid, it is a strong reactive oxygen species (ROS) scavenger and good metal chelator, rich in phenolic hydroxyl groups that have strong antioxidant activity. For the present study, the strong antioxidant activity of QUR on several biochemical parameters in blood and liver of male rats exposed to high fat diet (HFD) induced non alcoholic steatohepatitis (NASH), were investigated. Sixty white male albino rats weighting 150 - 200 gm were used in this study. The rats were divided into four equal groups. 1) Normal group: received no drugs. 2) NASH group: received HFD daily for 12 weeks. 3) NASH + Quercetin group: received HFD daily for 3 months then QUR treatment $(50 \mathrm{mg} / \mathrm{kg}$ body weight) through intraperitoneal route (i.p) daily for 10 weeks after induction of NASH. Blood and liver samples were collected from all animal groups two times, after the $6^{\text {th }}$ and $10^{\text {th }}$ week of treatment period. Serum was separated for determination of serum Alanine Aminotransferase (ALT), Aspartate Aminotransferase (AST), Alkaline Phosphatase (ALP) and Gamma Glutamyl-Transferase ( $\gamma$-GT) activities and Albumin, Total Protein, Total Bilirubin, Total Cholesterol and triglycerides concentrations. Levels of reduced glutathione (GSH) and activities of Superoxide Dismutase (SOD) and Catalase (CAT), were determined in liver tissues. Extent of oxidative stress was also assessed by hepatic lipid peroxides (MDA). The obtained results revealed that, HFD supplementation exhibited a significant increase in: 1) serum ALT, AST, ALP and $\gamma$-GT activities, in addition to Total Bilirubin, Total Cholesterol and triglycerides concentrations. 2) Liver MDA concentration. QUR administration in NASH rats exhibited a significant increase in all mentioned parameters. On contrast, HFD supplementation exhibited a significant decrease in serum Albumin and Total Protein, also marked depletion in liver GSH, CAT and SOD, were observed. QUR administration in NASH rats exhibited significant increase in all mentioned parameters. From the obtained results, it could be concluded that, the potential of QUR as natural antioxidant act as a powerful agent against the harmful effects of NASH.
\end{abstract}

Keywords: Quercetin, Flavonoids, Oxidative stress, NASH, NAFLD, High fat diet.

\section{Introduction}

Nonalcoholic fatty liver disease (NAFLD) represents a spectrum of liver diseases that occur in individuals who do not consume a significant amount of alcohol, extending from pure fatty liver through nonalcoholic steatohepatitis (NASH) to cirrhosis and hepatocarcinoma [1]. NAFLD has emerged as a worldwide common problem that represents the most frequent histological finding in individuals with abnormal liver tests in the Western countries [2].

Non-alcoholic steatohepatitis is a pathological condition characterized by accumulation of lipids in the liver of non-alcoholic individuals and consequent oxidative stress leading to cirrhosis of liver in the long run [3]. It has received clinical importance only recently after a long lag phase of ignorance mainly due to its asymptotic nature, lack of relevant diagnostic tests and erroneous misinterpretation with hepatitis [4].

Although the pathogenesis of NAFLD remains undefined, the so called 'two hits' model of pathogenesis has been proposed [5]. Whereas the 'first hit' involves the accumulation of fat in the liver, the 'second hit' involves oxidative stress, resulting in inflammation, stellate cell activation and fibrogenesis [6].
On the other hand, NASH is a more advanced stage of NAFLD, since the chances of developing more serious diseases such as cirrhosis, hepatocellular carcinoma(HCC), and cardiovascular diseases increase in patients with NASH [7].

Mitochondrial dysfunction might play a crucial role in the induction of both 'hits', because mitochondria are involved in the $\beta$-oxidation of free fatty acids, and are the most important source of reactive oxygen species (ROS) [1].

Quercetin (3,3',4',5,7-pentahydroxy flavones) is a flavonoid antioxidant derived from flavonol subclass which is present in plants and plant food sources [8]. QUR and its derivatives have been promoted in several studies as potent antioxidants [9]. It is rich in phenolic hydroxyl groups that have strong antioxidant activity [10]. In addition, QUR possesses a number of pharmacological activities including antioxidant, anticancer, antimicrobial, and antiviral [11]. In recent studies, QUR was reported to protect against drug-induced genotoxicity, hepatotoxicity, nephrotoxicity, lung injury, and oxidative stress in vivo [12]. Also it has been used to treat hepatotoxicity, liver fibrosis, and many diseases [13]. 
Quercetin can also reduce inflammation by scavenging free radicals. Free radicals can activate transcription factors that generate pro-inflammatory cytokines, which are often found elevated in patients that suffer from chronic inflammatory diseases [14].

High concentrations of QUR are found in apples, onions, potatoes, broccoli, tea, soybeans, and red wine. QUR has very potent antioxidant and cytoprotective effects in preventing endothelial apoptosis caused by oxidants [15].
2. Materials and methods

2.1 Composition of high fat diet

Formulated according to [16]. Table (1)

\subsection{Chemicals}

Quercetin (purity 95\%) was manufactured in Sigma Chemical Co. (St. Louis, Mo, USA) and purchased from Schnelldorf, Germany through the Egyptian International Center for Import Cairo, Egypt. It is characterized by high solubility in DMSO $(68 \mathrm{mg} / \mathrm{ml})$. All other chemicals were of analytical grade and were obtained from standard commercial suppliers.

Table (1) Composition of high fat diet (For induction of NASH)

\begin{tabular}{lccc}
\hline Composition & High fat diet $\mathbf{( g / k g )}$ & Composition & High fat diet $(\mathbf{g} / \mathbf{k g})$ \\
\hline Casein & 200 & Corn starch & 275 \\
Saturated fat & 200 & Sucrose & 80 \\
Corn oil & 150 & Dextrin & 50 \\
Cholesterol & 3 & Fructose & 5 \\
Amino acids & 5 & NaCl & 5 \\
Vitamins & 10 & Cellulose & 5 \\
Moisture & 12 & & \\
\hline
\end{tabular}

\subsection{Experimental animals}

A total number of 60 Male albino rats, 8-10 weeks old and average body weight 150-200 gm were used in the experimental investigation of this study, and obtained from the Laboratory Animals Research Center, Fac. Vet. Med., Benha University, Rats were housed in separated metal cages, exposed to good ventilation, humidity and to a 12-hr lightdark cycle, and provided with a constant supply of standard pellet diet and clean drinking water ad libitum.

\subsection{Preparation and administration of dosage}

Quercetin was freshly prepared in DMSO, and administered to rats at a dose of $(50 \mathrm{mg} / \mathrm{kg}$ body wt.) through intraperitoneal route (i.p) between 7 and 8 a.m. daily for 10 weeks as a treatment after induction of NASH for 12 weeks.

\subsection{Experimental design}

Rats were randomly divided into three main groups ( $n=20 /$ group), placed in individual cages and classified as following: (Group 1): served as control normal group (20 rats); (Group 2): served as induced NASH group (20 rats) fed on high fat diet for 3 months; (Group 3): served as NASH + Quercetin treated group (20 rats) fed on high fat diet for 3 months for induction of NASH followed by administration with quercetin $(50 \mathrm{mg} / \mathrm{kg}$ body weight) intraperitoneally, between 7 and 8 a.m. daily for 10 weeks as a treatment.

\subsection{Sampling}

A. Blood samples

Blood samples were collected from retroarbitral plexus, from all animal groups twice at $6^{\text {th }}$ and $10^{\text {th }}$ week of treatment period. rats were fasted overnight and Blood samples were collected in dry, clean, screw capped tubes and allowed to clot for $30 \mathrm{~min}$ and serum was separated by centrifugation at $3000 \mathrm{rpm}$ for $15 \mathrm{~min}$ at $4{ }^{\circ} \mathrm{c}$. The serum was separated by automatic pipette and received in dry sterile tubes, kept in a deep freezer at $-20{ }^{\circ} \mathrm{c}$ until used for subsequent biochemical analysis.

\section{B. Liver specimens}

Rats were killed by decapitation. The liver specimens quickly removed, cleaned by rinsing with cold saline and stored at $-20^{\circ} \mathrm{C}$. Briefly, liver tissues were minced into small pieces, homogenized in normal saline $0.9 \%$. The homogenates were centrifuged at 10,000 for 15 minute at $4^{\circ} \mathrm{C}$. The supernatant was used for estimation of L-MDA, GSH concentration and CAT, SOD activity.

\subsection{Determination of key liver function biochemical markers}

ALT and AST [17], [18], ALP [19], $\gamma$-GT [20], Total bilirubin [21], Albumin [22], Total Protein [23], Total cholesterol [24], Triacylglycerols [25]. 


\subsection{Determination of key oxidative stress markers}

GSH [26], MDA [27], CAT [28], SOD [29], were determined according to the methods described previously.

\subsection{Statistical analysis}

The results were expressed as mean $( \pm$ S.E. $)$ and statistical significance was evaluated by one way ANOVA using SPSS (version 10.0) program followed by the post hoc test, least significant difference (LSD). Values were considered statistically significant when $\mathrm{p}<0.05$.

\section{Results}

The obtained data in table (2) revealed a significant increase in ALT, AST, ALP and $\gamma$-GT activities, in addition to levels of Total Bilirubin, Total Cholesterol and triacylglycerols in HFD induced NASH group, accompanied with significant decrease in Albumin and Total protein levels, when compared with control normal group. Administration of Quercetin as treatment to HFD induced NASH group, resulted in significant decreases in ALT, AST, ALP and $\gamma$-GT activities, in addition to levels of Total Bilirubin, Total Cholesterol and triglycerides, accompanied with significant increases in Albumin and Total protein levels, in comparison with NASH group.

The obtained data in table (3) revealed that, supplementation of HFD to normal rats exhibited a significant increase in L-MDA level and significant decreases in GSH level, CAT and SOD activities in liver of HFD induced NASH group, when compared with control normal group. Quercetin administration to NASH rats resulted in significant decrease in L-MDA level and significant increases in GSH level, CAT and SOD activities in its liver, when compared with NASH group

Table (2) The ameliorating role of Quercetin on blood biochemical parameters in experimental model of NASH in male rats.

\begin{tabular}{|c|c|c|c|c|c|c|c|c|c|c|}
\hline & $\begin{array}{l}\text { Animal } \\
\text { groups }\end{array}$ & $\begin{array}{l}\mathbf{A L T} \\
\mathbf{U} / \mathbf{L}\end{array}$ & $\begin{array}{l}\mathbf{A S T} \\
\mathbf{U} / \mathbf{L}\end{array}$ & $\begin{array}{l}\mathbf{A L P} \\
\mathbf{U} / \mathbf{L}\end{array}$ & $\begin{array}{c}\gamma-\mathbf{G T} \\
\mathbf{U} / \mathbf{L}\end{array}$ & $\begin{array}{c}\text { Bilirubin } \\
(\mathrm{mg} / \mathrm{dl})\end{array}$ & $\begin{array}{c}\text { Albumin } \\
\text { (g/dl) }\end{array}$ & $\begin{array}{c}\text { Protein } \\
\text { (g/dl) }\end{array}$ & $\begin{array}{l}\text { T. Chol } \\
\text { (mg/dl) }\end{array}$ & $\begin{array}{c}\text { TAG } \\
(\mathrm{mg} / \mathrm{dl})\end{array}$ \\
\hline \multirow{9}{*}{$\begin{array}{c}\text { After } \\
6^{\text {th }} \\
\text { week }\end{array}$} & \multirow{3}{*}{$\begin{array}{l}\text { Control } \\
\text { normal }\end{array}$} & 40.57 & 119.28 & 194.85 & 2.01 & 0.39 & 3.78 & 7.27 & 72.14 & 59.03 \\
\hline & & \pm & \pm & \pm & \pm & \pm & \pm & \pm & \pm & \pm \\
\hline & & $1.46^{\mathrm{c}}$ & $1.92^{c}$ & $2.46^{\mathrm{c}}$ & $0.10^{\mathbf{c}}$ & $1.67^{\mathrm{c}}$ & $5.83^{\mathrm{a}}$ & $0.13^{\mathrm{a}}$ & $2.84^{\mathrm{c}}$ & $2.20^{\mathrm{c}}$ \\
\hline & \multirow{3}{*}{ NASH } & 215.14 & 355.28 & 454.42 & 7.60 & 1.35 & 2.15 & 4.42 & 349.85 & 402.85 \\
\hline & & \pm & \pm & \pm & \pm & \pm & \pm & \pm & \pm & \pm \\
\hline & & $5.85^{\mathrm{a}}$ & $8.41^{\mathrm{a}}$ & $8.36^{\mathrm{a}}$ & $0.28^{\mathrm{a}}$ & $5.24^{\mathrm{a}}$ & $7.36^{\mathrm{c}}$ & $0.12^{\mathrm{c}}$ & $5.97^{\mathrm{a}}$ & $6.15^{\mathrm{a}}$ \\
\hline & \multirow{3}{*}{$\begin{array}{l}\text { NASH+ } \\
\text { Quercetin }\end{array}$} & 130.14 & 192.67 & 352.14 & 5.36 & 0.83 & 2.93 & 5.43 & 182.11 & 154.85 \\
\hline & & \pm & \pm & \pm & \pm & \pm & \pm & \pm & \pm & \pm \\
\hline & & $3.12^{\mathrm{b}}$ & $3.45^{\mathrm{b}}$ & $4.54^{\mathrm{b}}$ & $0.25^{\mathrm{b}}$ & $3.97^{\mathbf{b}}$ & $4.01^{b}$ & $0.28^{\mathbf{b}}$ & $4.09^{b}$ & $4.47^{\mathbf{b}}$ \\
\hline \multirow{9}{*}{$\begin{array}{c}\text { After } \\
10^{\text {th }} \\
\text { week }\end{array}$} & \multirow{3}{*}{$\begin{array}{l}\text { Control } \\
\text { normal }\end{array}$} & 48.34 & 136.08 & 213.85 & 2.51 & 0.45 & 3.61 & 6.98 & 79.18 & 66.85 \\
\hline & & \pm & \pm & \pm & \pm & \pm & \pm & \pm & \pm & \pm \\
\hline & & $1.54^{\mathrm{c}}$ & $1.79^{c}$ & $2.97^{\mathrm{c}}$ & $0.15^{\mathrm{c}}$ & $2.26^{\mathrm{c}}$ & $3.48^{\mathrm{a}}$ & $0.12^{\mathrm{a}}$ & $2.61^{\mathrm{c}}$ & $2.09^{c}$ \\
\hline & \multirow{3}{*}{ NASH } & 257.00 & 377.42 & 467.42 & 8.66 & 1.62 & 1.92 & 3.99 & 377.57 & 443.42 \\
\hline & & \pm & \pm & \pm & \pm & \pm & \pm & \pm & \pm & \pm \\
\hline & & $4.75^{\mathrm{a}}$ & $3.61^{\mathrm{a}}$ & $7.38^{\mathrm{a}}$ & $0.29^{\mathrm{a}}$ & $6.02^{a}$ & $5.97^{\mathrm{c}}$ & $0.13^{\mathrm{c}}$ & $4.43^{\mathrm{a}}$ & $4.60^{\mathrm{a}}$ \\
\hline & \multirow{3}{*}{$\begin{array}{l}\text { NASH+ } \\
\text { Quercetin }\end{array}$} & 121.57 & 179.26 & 317.71 & 4.69 & 0.71 & 3.08 & 6.05 & 164.47 & 136.18 \\
\hline & & \pm & \pm & \pm & \pm & \pm & \pm & \pm & \pm & \pm \\
\hline & & $3.13^{\mathrm{b}}$ & $3.89^{b}$ & $4.12^{b}$ & $0.24^{\mathbf{b}}$ & $3.50^{\mathrm{b}}$ & $4.22^{b}$ & $0.24^{\mathbf{b}}$ & $3.46^{\mathrm{b}}$ & $3.65^{b}$ \\
\hline
\end{tabular}

Data shown are mean \pm standard deviation of number of observations within each treatment. Mean values with different superscript letters in the same column are significantly different at $(\mathrm{P}<0.05)$. Small letters are used for comparison between the means within the column.

Table (3) The ameliorating role of Quercetin on liver antioxidant parameters in experimental model of NASH in male rats.

\begin{tabular}{|c|c|c|c|c|c|c|c|c|}
\hline \multirow[b]{2}{*}{$\begin{array}{l}\text { Animal } \\
\text { groups }\end{array}$} & \multicolumn{2}{|c|}{$\begin{array}{c}\text { L-MDA } \\
\text { (nmol/g. tissue) }\end{array}$} & \multicolumn{2}{|c|}{$\begin{array}{c}\text { GSH } \\
\text { (mg/g. tissue) }\end{array}$} & \multicolumn{2}{|c|}{$\begin{array}{c}\text { Catalase } \\
\text { (U/g. tissue) }\end{array}$} & \multicolumn{2}{|c|}{$\begin{array}{c}\text { SOD } \\
\text { (U/g. tissue) }\end{array}$} \\
\hline & $\begin{array}{c}6^{\text {th }} \\
\text { week }\end{array}$ & $\begin{array}{c}10^{\text {th }} \\
\text { week }\end{array}$ & $\begin{array}{c}6^{\text {th }} \\
\text { week }\end{array}$ & $\begin{array}{c}10^{\text {th }} \\
\text { week }\end{array}$ & $\begin{array}{c}6^{\text {th }} \\
\text { week }\end{array}$ & $\begin{array}{c}10^{\text {th }} \\
\text { week }\end{array}$ & $\begin{array}{c}6^{\text {th }} \\
\text { week }\end{array}$ & $\begin{array}{c}10^{\text {th }} \\
\text { week }\end{array}$ \\
\hline $\begin{array}{l}\text { Control } \\
\text { normal }\end{array}$ & $\begin{array}{c}64.80 \\
\pm 2.75^{c}\end{array}$ & $\begin{array}{c}67.48 \\
\pm 2.35^{c}\end{array}$ & $\begin{array}{c}96.55 \\
\pm 3.46^{\mathrm{a}}\end{array}$ & $\begin{array}{l}93.31 \\
\pm 3.44^{\mathrm{a}}\end{array}$ & $\begin{array}{c}65.57 \\
\pm 3.07^{\mathrm{a}}\end{array}$ & $\begin{array}{c}62.28 \\
\pm 1.97^{c}\end{array}$ & $\begin{array}{l}455.14 \\
\pm 9.82^{\mathrm{a}}\end{array}$ & $\begin{array}{l}434.58 \\
\pm 7.79^{\mathrm{a}}\end{array}$ \\
\hline NASH & $\begin{array}{r}174.58 \\
\pm 3.42^{\mathrm{a}}\end{array}$ & $\begin{array}{r}186.29 \\
\pm 3.36^{\mathrm{a}}\end{array}$ & $\begin{array}{c}35.35 \\
\pm 2.13^{c}\end{array}$ & $\begin{array}{c}31.23 \\
\pm 2.07^{\mathrm{c}}\end{array}$ & $\begin{array}{c}27.14 \\
\pm 1.79^{c}\end{array}$ & $\begin{array}{r}23.42 \\
\pm 1.67^{\mathrm{a}}\end{array}$ & $\begin{array}{l}188.47 \\
\pm 4.05^{\mathrm{c}}\end{array}$ & $\begin{array}{l}171.25 \\
\pm 3.91^{\mathrm{c}}\end{array}$ \\
\hline $\begin{array}{c}\text { NASH + } \\
\text { Quercetin }\end{array}$ & $\begin{array}{l}115.89 \\
\pm 3.72^{b}\end{array}$ & $\begin{array}{c}93.40 \\
\pm 3.60^{b}\end{array}$ & $\begin{array}{c}61.42 \\
\pm 3.35^{b}\end{array}$ & $\begin{array}{c}69.09 \\
\pm 2.80^{b} \\
\end{array}$ & $\begin{array}{c}38.29 \\
\pm 2.94^{\mathrm{b}} \\
\end{array}$ & $\begin{array}{c}43.63 \\
\pm 2.89^{b}\end{array}$ & $\begin{array}{l}331.54 \\
\pm 5.47^{\mathbf{b}}\end{array}$ & $\begin{array}{l}348.85 \\
\pm 3.68^{b}\end{array}$ \\
\hline
\end{tabular}

Data shown are mean \pm standard deviation of number of observations within each treatment. Mean values with different superscript letters in the same column are significantly different at $(\mathrm{P}<0.05)$. Small letters are used for comparison between the means within the column. 


\section{Discussion}

The purpose of the present study was to evaluate the effects of QUR on the inhibition of HFD-induced steatohepatitis in rats as well as to assess the action of this antioxidant on hepatic oxidative stress and hepatocellular injury.

Experimental diets represent a useful tool in research because they deliver quick results for the study of disease progression. Because they allow a better understanding of the physiopathology and mechanisms involved in the transition from steatosis to NASH [30], experimental models of NASH are of paramount importance in testing the effectiveness of various available drugs for treatment.

In this work, a pharmacological dose of QUR was tested, which deserves further investigation into its potential for clinical use. Here, it was observed that QUR inhibited the development of NASH by a significant reduction in AST and ALT, AST, ALP, $\gamma$-GT, lipid peroxidation and inflammation.

Increased lipid peroxidation has been demonstrated in animal models of fatty liver with NASH. Free fatty acids (FFAs) are the likely source of oxidative stress within the liver in this case. NASH group have increased lipolysis and increased delivery of FFAs to the liver. The products of FFA oxidation (hydrogen peroxide, superoxide, and lipid peroxides) are capable of generating oxidative stress and subsequent lipid peroxidation [16].

Evidence of lipid peroxidation in the form of increased MDA production, a marker of oxidative stress, has been noted in previous studies and serum levels of MDA have been correlated with the severity of chronic hepatitis [31]. In the present study, liver MDA levels were significantly increased in experimental NASH, indicating increased oxidative stress. The defense against free radical-mediated injury includes enzymatic deactivation and direct reaction with free radicals [32]. However, QUR is a flavonoid known for its ability to give hydrogen atom to free radicals, decreasing the production of hydroxyl radical. This flavonoid can also modulate a wide range of mammalian enzyme activities, such as cytochrome P450 and several antioxidant enzymes [33].

In addition, quercetin significantly protected the membrane lipid peroxidation and protein oxidation subjected to oxidative stress, as evidenced by a decrease in the MDA level and protein carbonyl content. Also, the antioxidant activity may also be attributed to isoquercitrin which decreased the oxidative stress markers, such as levels of ROS, protein carbonylation and lipid peroxidation, and inducing the superoxide dismutase activity in order to increase survival of cells and leading to protection of the cells [34].

Cellular studies have shown that QUR can generate both antioxidant and pro-oxidant effects according to its concentration [35]. It has been proposed that cellular oxidative balance and GSH (Glutathione) content play a crucial role in these effects. GSH is a tripeptide consisting of glutamate, cysteine, and glycine, and the antioxidant and conjugation properties of GSH are derived from the sulfhydryl moiety of the cysteine deposit. GSH is able to directly hunt down the cellular ROS in a non-enzymatic manner and is also able to function as a co-factor for GSH peroxidase (GPx) in the reduction of $\mathrm{H} 2 \mathrm{O} 2$ and other peroxide types. GSH can also be employed in reactions involving disulphide exchanges to form mixed proteinglutathione disulphides, and the direct posttranslational conversion of proteins via the glutathionylation of the protein sulfhydryl groups is being recognized as a significant signal transduction mechanism for controlling various cellular processes [36].

QUR raises the production of $\gamma$ glutamylcysteinesynthetase (GCS), which is a rate limiting enzyme, in the synthesis of the vital endogenous cellular antioxidant, GSH, which is needed for various cell functions and delivers bioreducing equivalents for numerous cellular reactions [33].

QUR can reduce inflammation by scavenging free radicals. Free radicals can activate transcription factors that generate pro-inflammatory cytokines, which are often found elevated in patients that suffer from chronic inflammatory diseases [14].

SOD, the first line of defense against oxygen derived free radicals, converts superoxide anion into $\mathrm{H} 2 \mathrm{O} 2$, forming as neutral products $\mathrm{O} 2$ and H2O. GSH-Px catalyses reductive destruction of hydrogen and lipid hydroperoxides, using glutathione as an electron donor [37]. The balance between oxidative stress and antioxidant defense mechanisms may be impaired by depletion of enzymatic antioxidants and decreased serum levels of MDA and NO in patients with NASH.

In response to oxidative stress, there is usually an increased synthesis of antioxidants and ROS scavengers. However, changes in the activities of the liver antioxidant enzymes and their relationships to oxidative stress have inadequately been studied in patients with NASH [16].

The body protects itself from oxygen free radical toxicity by enzymatic antioxidant mechanisms (e.g. glutathione peroxidase (GSH-Px), glutathione reductase (GR), superoxide dismutase (SOD), and catalase) and by non-enzymatic antioxidants [38]. The emerging ROS in NASH condition are successfully neutralized by a cell through both antioxidant enzyme systems such as SOD GPx, CAT and low molecular compounds such as glutathione, melatonin and others [39].

The present study demonstrated that failure of antioxidant defense mechanisms against oxidative stress may be an important factor in the 
pathogenesis of NASH. Decreased glutathione levels have been reported in NASH patients [40]. Therefore, patients with NASH have an impaired ability to produce sufficient antioxidants. This may be related to the recently observed decrease in three genes involved in $\mathrm{ROS}$ sequestration $(\mathrm{Cu} / \mathrm{Zn}$ superoxide dismutase, glutathione peroxidase, and catalase) in cirrhosis secondary to NASH. GST has an important role in antioxidant defense system at the cellular level and is a valuable marker of oxidative stress in NASH [41].

The antioxidant properties of QUR have been investigated quite extensively, and there is evidence that they involve direct [42] scavenging of radicals as well as indirect activation of transcription factors that regulate the expression of genes encoding for antioxidant enzymes, including CAT and SOD [43]. In our study, we observed a significant decrease in the enzymes CAT and SOD, in the NASH groups; this can be explained by an attempt to reduce ROS generated by the systemic consumption of CAT.

The antioxidant and hepatoprotective activities of the flavonoid quercetin can ameliorate acute liver damage by acting as scavengers of free radicals, inhibiting the inflammatory response, manifested by a decreased deposition of fats in liver cells; thereby it protects liver cells from fibrosis and reduces plasma concentration of ALT thus exerting high antioxidant and anti-inflammatory activities and antifibrotic action and may be partially responsible for beneficial effects observed in injured liver tissue [34].

The predominance of QUR in preventing both metal and non-metal-induced oxidative damage is partly attributed to its free $3-\mathrm{OH}$ substituent which is believed to increase the stability of the flavonoid radical. The catechol group is also directly connected to the chelating action of QUR, as has been proven by various studies in which quercetin suppresses lipid peroxidation by the scavenging action of its free radical [44].

\section{Conclusion}

From the obtained results, it could be concluded that, NASH induced by HFD extensively alters and induced disturbances in enzymatic and nonenzymatic antioxidant system in liver tissue of rats. However, quercetin administration as a natural antioxidant efficiently protects liver from deleterious effect of oxidative stress induced by NASH. We recommended that, we can take advantage of the great therapeutic effects of quercetin by its administration for patients suffering from NASH.

\section{References}

[1] I.García-Ruiz, P.Solís-Muñoz, D.FernándezMoreira, M.Grau, F.Colina, T.Muñoz-Yagüe, J.A.Solís-Herruzo, High-fat diet decreases activity of the oxidative phosphorylation complexes and causes nonalcoholic steatohepatitis in mice. Disease Models \& Mechanisms Vol.7, PP.1-10, 2014.

[2] A.J.McCullough, The epidemiology and risk factors of NASH. In Fatty Live Disease. NASH and Related Disorders (ed. G.C. Farrell, J. George, P. de la M. Hall and A. J. McCullough), Malden, MA: Wiley-Blackwell. PP.23-37, 2005.

[3] M.Duvnjak, I.Lerotic, N.Baršic, V.Tomašic, L.V.Jukic, V.Velagic, Pathogenesis and management issues for non-alcoholic fatty liver disease. World J. Gastroenterol. Vol.13, PP.4539-4550, 2007.

[4] A.S.Dabhi, K.J.Brahmbhatt, T.P.Pandya, P.B.Thorat, M.C.Shah, Nonalcoholic fatty liver disease (NAFLD). J. Ind. Acad. Clin. Med. Vol.9, PP.36-41, 2008.

[5] C.P.Day, O.F.James, Steatohepatitis: a tale of two "hits"? Gastroenterology. Vol.114, PP.842845, 1998.

[6] S.Chitturi, G.C.Farrell, Etiopathogenesis of nonalcoholic steatohepatitis. Semin. Liver Dis. Vol.21, PP.27-42, 2001.

[7] C.Brenner, L.Galluzzi, O.Kepp, G.Kroemer, Decoding cell death signals in liver inflammation, Journal of Hepatology, Vol.59(3), PP.583-594, 2013.

[8] K.Sikder, N.Das, S.B.Kesh, S.Dey, Quercetin and B-sitosterol prevents high fat diet induced dyslipidemia and hepatotoxicity in swiss albino mice. Indian J. Exp. Biol. Vol.52, PP.60-66. 2014.

[9] K.B.Magalingam, A.Radhakrishnan, N.,Haleagrahara, Protective effects of flavonol isoquercitrin, against 6-hydroxy dopamine (6OHDA)-induced toxicity in PC12 cells. BMC Res. Notes, Vol.7, PP.49-56, 2014.

[10] C.Tokyol, S.Yilmaz, A.Kahraman, H.Cakar, C.,Polat, The effects of desferrioxamine and quercetin on liver injury induced by hepatic ischaemia-reperfusion in rats. Acta Chirurgica Belgica, Vol.106, PP.68-72, 2006.

[11] A.Maalik, F.A.Khan, A.Mumtaz, A.Mehmood, S.Azhar, M.Atif, S.Karim, Y.Altaf, I.Tariq, Pharmacological Applications of Quercetin and Its Derivatives: A Short Review. Trop. J. Pharm. Res. Vol.13, PP.1561-1566, 2014.

[12] G.I.Qader, R.S.Aziz, Z.A.Ahmed, Z.F.Abdullah, S.A.Hussain, Protective Effects of Quercetin against Isoniazid and Rifampicin 
Induced Hepatotoxicity in Rats. Am. J. Pharmacol. Sci. Vol.2, PP.56-60, 2014.

[13] J.Tieppo, M.J.Cuevas, R.Vercelino, M.J.Tunon, N.P.Marroni, J.Gonzalez-Gallego, Quercetin administration ameliorates pulmonary complications of cirrhosis in rats. Journal of Nutrition, Vol.139, PP.1339-1346, 2009.

[14] A.W.Boots, L.C.Wilms, E.L.Swennen, J.Kleinjans, A.Bast, G.R.Haenen, In vitro and ex vivo anti-inflammatory activity of quercetin in healthy volunteers. Nutrition. Vol.24(7), PP.703-710, 2008.

[15] J.Renugadevi, S.M.Prabu, Quercetin protects against oxidative stress-related renal dysfunction by cadmium in rats. Experimental and Toxicologic Pathology, Vol.62, PP.471481, 2010.

[16] K.M.Surapaneni, M.Jainu, Comparative effect of pioglitazone, quercetin and hydroxy citric acid on the status of lipid peroxidation and antioxidants in experimental non-alcoholic steatohepatitis. journal of physiology and pharmacology. Vol.65(1), PP.67-74, 2014.

[17] R.Murray, Alanine aminotransferase. Kaplan A et al. Clin Chem The C.V. Mosby Co. St Louis. Toronto. Princeton Vol.96., PP.10881090, 1984.

[18] R.Murray, 1984. Aspartate aminotransferase. Kaplan A et al. Clin Chem The C.V. Mosby Co. St Louis. Toronto. Princeton Vol.96, PP.1112-1116, 1984.

[19] S.B.Rosalki, A.Y.Foo, A.Burlina, et al., Multicenter evaluation of iso-ALP test kit for measurement of bone alkaline phosphatase activity in serum and plasma. Clin Chem Vol.39, PP.648-652, 1993.

[20] D.H.Lee, kinetic colorimetric method for determination of $\gamma$-GT activity. Clin. Chem. Vol.49, PP.1358-1366, 2003.

[21] A.Kaplan, et al., Bilirubin. Clin Chem The C.V. Mosby Co. St Louis. Toronto. Princeton; Vol. 436, PP.1238-1241, 1984.

[22] B.T.Doumas, et al., Clin. Chim. Acta, PP.3187, 1971

[23] A.Kaplan, J.Szalbo, Clinical chemistry :Interpretation and techniques, 2 nd ed. A Kaplan, J Szabo, editors, Vol.94, PP.157, 1983.

[24] F.Meiattini et al., The 4-hydroxybenzoate/4aminophenazone Chromogenic System. Clin Chem Vol.24(12), PP.2161-2165, 1978.

[25] G.Buccolo, et al., Quantitative determination of serum triglycerides by use of enzymes. Clin Chem, Vol.19(5), PP.476-482, 1973.

[26] E.Beutler, O.Duron, M.B.Kelly, J. Lab Clin. Med.Vol.61, PP.882, 1963.
[27] H.Ohkawa, W.Ohishi, K.Yagi, Anal. Biochem Vol.95, PP.351, 1979.

[28] H.Aebi, Methods Enzymol. Vol.105, PP.121$126,1984$.

[29] M.Nishikimi, N.A.Roa, K.Yogi, Biochem. Bioph. Res. Common., Vol.46, PP.849-854, 1972.

[30] C.Z.Larter, M.M.Yeh, Animal models of NASH: getting both pathology and metabolic context right. J Gastroenterol Hepatol., Vol.23, PP.1635-48, 2008.

[31] D.Yadav, H.I.Hertan, P.Schweitzer, E.P.Norkus, C.S.Pitchumoni, Serum and liver micronutrient antioxidants and serum oxidative stress in patients with chronic hepatitis C. Am J Gastroenterol, Vol.7, PP.2634-2649, 2002.

[32] P.DiMascio, M.E.Murphy, H.Sies, Antioxidant defense systems: the role of the carotenoids, tocopherols and thiols. Am J Clin Nutr., Vol.53, PP.194-200, 1991.

[33] N.S.Alrawaiq, A.Abdullah, A Review of Flavonoid Quercetin: Metabolism, Bioactivity and Antioxidant Properties. International Journal of PharmTech Research, Vol.6, No.3, PP.933-941, 2014.

[34] H.E.Hanaa, M.L.Rola, S.A.Nagy, A.H.Manal, A.R.,Samir, Hepatoprotective and antioxidant polyphenols from a standardized methanolic extract of the leaves of Liquidambar styraciflua L. Bulletin of Faculty of Pharmacy, Cairo University, Vol.53(2), PP.117-127, 2015.

[35] A.J.Vargas, R.Burd, Hormesis and synergy: pathways and mechanisms of quercetin in cancer prevention and management. Nutrition reviews. Vol.68(7), PP.418-428. 2010.

[36] M.Bredel, J.Zentner, Brain-tumour drug resistance: the bare essentials. The lancet oncology. Vol.3(7), PP.397-406, 2002.

[37] E.D.Harris, Regulation of antioxidant enzymes. FASEB J., Vol.6, PP.2675-83, 1992.

[38] Blokhina, O. Virolainen, E. Fagerstedt, K.V. Antioxidants, oxidative damage and oxygen deprivation stress: a review. Ann Bot, Vol.91, PP.179-194, 2003.

[39] Gonciarz M, Gonciarz Z, Bielanski W, et al. The effects of long-term melatonin treatment on plasma liver enzymes levels and plasma concentrations of lipids and melatonin in patients with non-alcoholic steatohepatitis: a pilot study. J Physiol Pharm 2012; 63: 35-40.

[40] G.Vendeniale, I.Grattagliano, P.Caraceni, et al., Mitochondrial oxidative injury and energy metabolism alteration in rat fatty liver: effect of the nutritional status. Hepatology Vol.33, PP.808-815, 2001. 
[41] M.Irie, T.Sohda, K.Iwata, et al., Levels of the oxidative stress marker gamma glutamyltranspeptidase at different stages of non-alcoholic fatty liver disease. J Int Med Res Vol.40, PP.924-933, 2012.

[42] G.N.Kim, H.D.Jang, Protective mechanism of quercetin and rutin using glutathione metabolism on HO-induced oxidative stress in HepG2 cells. Ann N.Y Acad Sci, Vol.1171, PP.530-537, 2009.
[43] G.R.Barcelos, J.P.Angeli, J.M.Serpeloni, et al., Quercetin protects human-derived liver cells against mercury-induced DNA-damage and alterations of the redox status. Mutat Res; Vol.726, PP.109-115, 2011.

[44] A.Ratty, N.Das, Effects of flavonoids on nonenzymatic lipid peroxidation: structureactivity relationship. Biochemical medicine and metabolic biology. Vol.39(1), PP.69-79, 1988. 